\title{
CHANGES IN INTERNATIONAL BUSINESS FORMS IN THE CONTEXT OF SUSTAINABLE DEVELOPMENT
}

\author{
Stela Zhivkova ${ }^{1}$
}

\begin{abstract}
Nowadays, sustainable development is much discussed and is regarded as a very important issue. It is all around us, in every part of our everyday life. It inevitably leads to changes in the economic and social behavior of every country even though these changes in the different economic areas are not well explored yet. Highlighting and identifying them, specifically in the field of international business operations, lead to development and implementation of a scientific research project called "Global challenges in the environment protection and changes in the international business." The research interest was focused on studying the changes in the international business operations in the context of environmental protection on the basis of two specific environmental pollutants - waste and greenhouse gas emissions. The main methods used were reviews and analysis of literature in the field of sustainable development and international business, critical analysis of the EU policies for waste minimization and climate change mitigation, practical experience, and experts' opinion.

The project results showed that in sustainable development conditions, new economic activities emerge such as bio-trade, production of bio-goods, and consultancy services on environmental issues. Some well-known activities, such as public procurement or public-private partnership, are getting green. In the field of international business, the modifications are related to, for example, development of additional supply chain called "waste chain", import and export of pollutants, such as waste and emissions, etc. It turns out that most of these changes are a result of the numerous measures taken by the institutions on national and international level to stimulate a sustainable way of work. In this article, only a few of them are briefly discussed.
\end{abstract}

JEL Classification Numbers: F23, Q01, Q53, DOI: http://dx.doi.org/10.12955/cbup.v2.450

Keywords: international business, sustainable development, environment, waste, greenhouse gas emissions

\section{Introduction}

In today's world, characterized by high technologies, constantly developing and improving manufacturing processes unique in its size for globalization, international business in all its forms is an integral part of the economic life of any society. It significantly contributes to the gross domestic product of developed countries and to the economic growth of developing countries. Nowadays, however, one of the biggest problems of the modern world turns out to be the constantly reducing amounts of resources. It is obvious now that the natural resources, used for production of different goods and for achieving higher lifestyle, are not unlimited. Climate changes, leading to various disasters, vanishing biodiversity, and decreasing amounts of potable water are all problems of great importance that have significant effect on the life of each society. This is the reason why, in the last decades, the concern is not only placed on reaching economic growth and better living conditions, but also on continuing in a sustainable manner. In this context, what matters most in today's globalized world is to achieve economic growth through sustainable development, by preserving the environment and keeping it for the next generations (Stiglitz, 2006). The sustainability issues are no longer something recommendable, or a matter of choice; they have become a necessity.

In the early $21^{\text {st }}$ century, sustainable development, with its three main pillars (economic development, social equity, and environment protection), is a part of our daily lives and economic system. In this respect, a lot of measures have been taken on national and international level to decrease the burden on the environment, and to protect it in the best possible way without seizing the economic development of the societies. These measures, although taken by the governments in the form of different policies or international agreements, inevitably influence the everyday business relations and operations.

The following section briefly presents some of the changes that have been identified in the forms of international business within research project called "Global challenges in the environment protection

\footnotetext{
${ }^{1}$ Stela Zhivkova, University for National and World Economy, Bulgaria, st_zhivkova@yahoo.com
} 
and changes in the international business." During the project, the attention was focused on one of the three sustainable development pillars - the environmental protection. We have tried to explore the changes that occurred in the forms of international business under the impact of the measures taken internationally to protect the environment and to save the natural resources. The focus was placed on exploring the changes that appeared in the international business, due to the international policies, in the field of waste generation reduction and climate change mitigation.

\section{The concept of sustainable development}

The issue of sustainable development in our time is extremely popular and widely discussed. There is a variety of sustainable development definitions and main characteristics. According to Bartelmus (1994), sustainable development is a development package, which helps to solve the conflict between the use of natural resources and social equality. It is a balance between social and environmental principles as socially justified, and environmentally sound economic development (Gechev, 2005). Another understanding of sustainable development defined it as a system of actions and mechanisms whose primary purpose is to ensure optimal growth of the economy through the use of natural resources in the most efficient manner, and to preserve them for future generations (Pearce, Barbier, \& Markandya, 1990). According to other authors, the essence of sustainable development lies in the fact that "each generation must satisfy their needs by taking into account the needs of future generations" (Davcheva-Ilcheva \& Ilchev, 2005).

These few visions, among many others, of sustainable development reflecting the different views on the global subject are summarized in a report titled "Our Common Future." This report was prepared in 1987 by the World Commission on Environment and Development, headed by Gro Brundtland and is better known as the "Brundtland Report." According to this report, sustainable development is the one "that meets the needs of the present without compromising the ability of future generations to meet their own needs" (WCED Report, 1987).

The concept of sustainable development is based on three domains or the so called "pillars," which are economic development, social equity, and environmental protection. In addition, the report formulates the following basic principles of sustainable development:

- priority should be given to improving the conditions of the world's poorest, and decisions should account for the rights of future generations;

- precautionary use of the natural resources and measures to prevent environmental degradation;

- integration between economic and environmental efficiency;

- equal environmental responsibility and cooperation between the States in solving the global problems of humanity.

This definition and the main principles of sustainable development provide the basis for the conclusion that its main characteristic is to enhance development of the society and its economic condition, by respecting and preserving the nature.

\section{International business and sustainable development}

The changes in international business forms, under the influence of environmental concerns, have been studied by analyzing the different international policies, specifically within the EU, in terms of waste minimization and climate change mitigation. In the research process some key trends, in the economy as a whole and in the international business forms in particular, were identified. 


\section{International business and waste management}

EU policy in the field of waste management is based on the Waste Management Framework Directive (Regulation 1013/2006/EC) for monitoring and control of shipments of waste within, into and from the EU, and several other directives regulating the activities with different specific waste streams. There is also a waste hierarchy, which has to be respected in waste treatment: prevention, preparation for re-use, recycling, other recovery (e.g. with the purpose of obtaining energy), and disposal (landfill). In the context of this EU policy for reducing the harmful effects of waste on the environment, it turned out that there are a lot of business opportunities for the companies. The economic entities are beginning to apply the well-known business operations in a new way, and modify them so as to comply with the legal requirements.

\section{Waste chain}

Traditional supply chain is linked to the production and economic activities, as well as the business sector and public organizations. It comprises of a group of customers and suppliers that buy, process, distribute, and sell products and services among each other (Boeva, 2004); the result is a specific end product. Supply chain includes the whole range of processes and activities performed in the production and supply that convert material and associated streams (Rakovska, 2007).

With the focus on environmental issues, the importance of the environmental behavior of various element suppliers within the supply chain increases. Employers (manufacturers) define criteria for environmental protection, which are applied to their suppliers throughout the entire supply chain. Thus, the supplies and the end products are converted into environmentally friendly ones. The application of this practice, on the whole supply chain, makes it "get green."

Faße, Grote, \& Winter (2009), in examining the relationship between environment and trade, even concluded that the supply chain is "embedded" in the environment because nature provides all relevant inputs and energy needed for the production processes.

Within this "greening" of the supply chain and the development of various policies for environmental protection, "waste chain" occurs. Figure 1 illustrates the process and general elements comprising a waste chain.

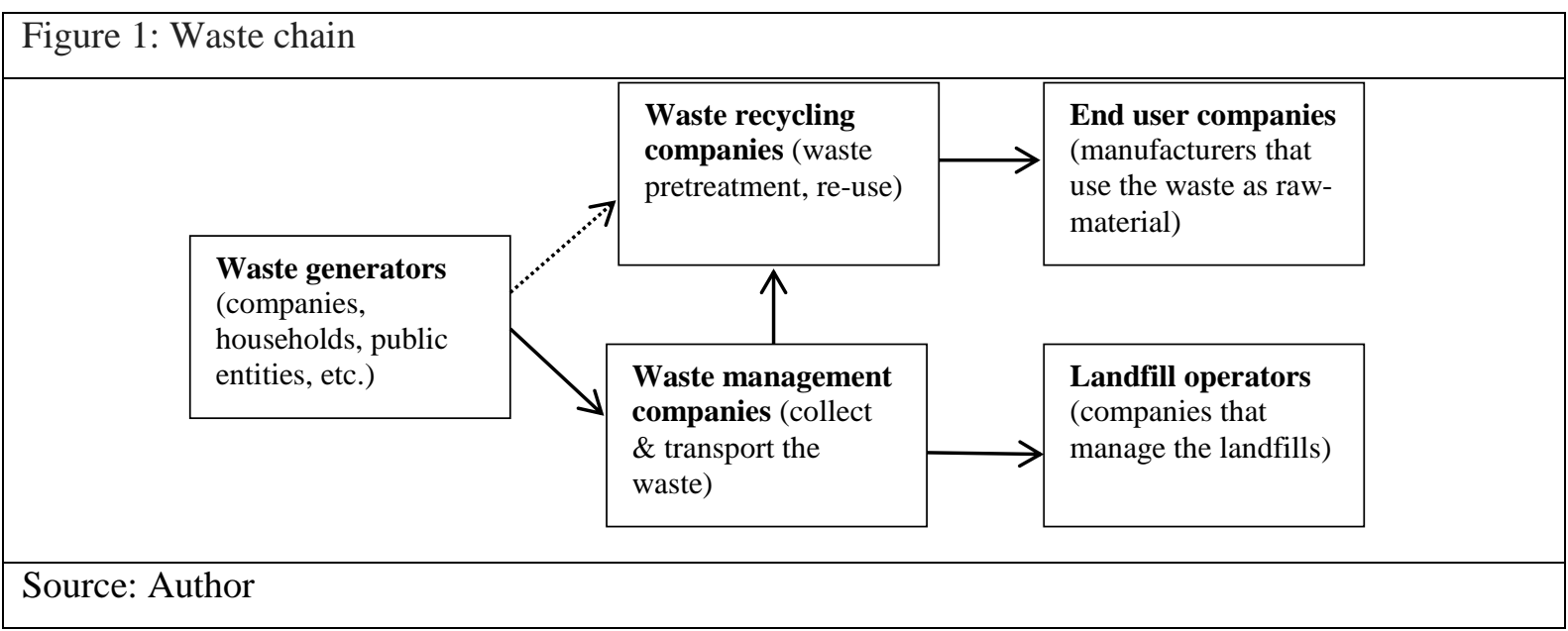

The first part of the chain is the "waste generators." They are all those who produce and dump waste; they are the households and all public and private entities.

The next step is the waste collection. It is usually handled by the so called "waste management companies." They collect and transport the waste, thus forming the next link in the chain. These companies specialize in collection and transportation of waste. In most cases, these entities do not deal with any other waste treatment activities, except for waste collection. They have contracts with the 
commercial and industrial entities for collection and transportation of their waste, and with the municipalities (which are responsible for the household waste) for the collection and disposal of the household waste. In developed countries, such as the Netherlands for example, the waste management companies might have contracts with the recycling companies to deliver the collected waste to them. Otherwise, they would transport it either directly to the landfill or to sites specifically appointed by the municipality. The waste is usually collected directly from the waste recycling companies; the recycling company collects and transports the waste with its own vehicles, thus avoiding contract arrangements with a third party.

The third link in the waste chain is the various companies that deal with pre-treatment and recycling of waste. These companies so called "recyclers," after receipt of the "commodity" or the waste in this case, sort it or process it as much as possible. The objective is to extract all valuable components that can be reused. Afterwards, they would transmit (sell) these components to other companies or the endusers.

End-users are typically manufacturing or processing plants that use waste as raw material in the production process. After processing the waste, they would get an entirely new product that will be delivered to the market. Such products can be recycled paper, various glass and plastic products, even computer accessories.

Thus, a new chain is formed with main commodity - the waste (Mahutga, 2011). In many cases of a search for better conditions or specific facilities for waste treatment, this chain goes internationally.

The waste chain is not exhaustive, but it provides a general idea about the changes that occur in the international business operations while trying to protect the environment.

\section{Export of waste}

In the EU, waste export is prohibited by Regulation 1013/2006/EC that regulates the supervision and control of waste. The purpose of this regulation is to prevent attempts to avoid the legal requirements for environmentally sound waste treatment. Although the waste export outside the individual country boundaries is prohibited, the Regulation allows certain opportunities for this to happen. The companies involved in waste management are capturing these opportunities, thus business relationships occur, with the waste as their main subject.

In accordance with the requirements of the Regulation, the exporting company must obtain special permission from the state authorities in order to export waste. This authorization, called "notification," must be submitted to the competent authorities of the importing country. The notification contains information about the type and amount of waste being shipped. Its specific characteristics also explain why and where waste is being shipped. Both the supplier of the waste (the exporter) and the processor or the facility that accepts the waste for disposal (the importer) must sign the notification. Such notification, in terms of commercial practice, can be seen as a type of contract with specific subject "supply of waste." For instance, in the Netherlands, companies involved in separate collection of paper and cardboard export them to China. They have specific trade contracts with Chinese companies that process this type of waste. Separately collected waste from electric and electronic equipment is exported to countries in Asia and Africa, to be processed at a much lower cost. Between 50 and $80 \%$ of the waste from electric and electronic equipment collected in the developed countries is exported to developing countries (Wang et al., 2012). There, it is processed and converted back into electric devices; and through the international trade, it is returned to the markets in the developed countries. 


\section{International Business and climate change}

Policies on climate change were also examined in the course of the project. International organizations began their attempts to limit air pollution back in the 1990s following the signing of the UN Framework Convention on Climate Change and the accompanying Kyoto Protocol. Kyoto Protocol contains specific targets for reducing greenhouse gas emissions for each State; the targets are binding and obligatory for all those have signed. Emission trading was one of the instruments (mechanisms) in the Protocol to encourage the economic entities to reduce their greenhouse gas emissions.

Emission trading is a scheme of exchanges, largely resembling the classic commodity exchanges, but carried out with some modifications. The trading object in the traditional commodity exchanges is qualitatively similar and exchangeable goods (Papadopoulos, 2011), whereas the main trading object in the emission trading exchange is "emission credits." While the participants in the traditional commodity exchanges are only brokers and speculators, the emissions trading exchanges allow the owners of the goods "carbon credits" (sellers and buyers) to participate. Participation can take place either by the companies themselves or by brokers who act on their behalf. Similar to the commodity exchanges, the emission trading exchanges may also have traders (speculators) who buy emission credits in order to resell them to interested parties while making marginal profits (Heindl, 2012).

Another similarity between traditional international commodity markets and international markets for emissions trading is in the form of creating, organizing, and managing the exchange; they can be private or public (Karakasheva et al., 2005). The first type of exchanges is built in the form of free associations of private firms or individuals; the second is built on the basis of regulations issued by public authority. Similar to the commodity exchanges, the emission trading schemes can either be public, when the scheme is legally defined and is mandatory for all large emission generators (this is the case with the European emissions trading scheme); or it can be private, when it is not legally defined but encourages the reduction of emissions generated on a regional basis or on the basis of private initiatives (Pinkse \& Kolk, 2008).

The main similarities and differences between classical organized markets and the newly emerging markets for emission trading are summarized in Table 1.

Table 1 provides the basis for extracting the main similarities between the two types of organized markets. Some of them are:

- the legal state of both the emission trading exchange and the traditional commodity exchange can either be public or private organizations;

- the exchange trade with emission allowances can be made by buyers and sellers, as well as by different mediators, such as brokers and dealers. This very much resembles the commodity exchange practice where the main participants are the mediators;

- the trade in both types of exchanges is done on the basis of standard contracts;

- both exchanges have very well developed clearing and settlement systems.

As shown in Table 1, some important differences between the newly organized market for emission allowances trading and the long-existing commodity exchanges are:

- the object of trading-environmental polluter $\left(\mathrm{CO}_{2}\right.$ emissions) is the traded commodity in the emission market;

- the presence of the product-in the emission trading exchanges, the goods are virtual and the trade itself is made virtually, unlike in traditional markets where are real tangible goods are physically delivered; 
- the verification process - this is completed by an independent third party, in order to obtain verification reports for the amounts of emission allowances. In traditional markets, the trade securities are set by specific compliance standards;

- account opening - an additional account for product delivery is required in order to participate in organized markets, unlike commodity trading where bank accounts are sufficient for financial transactions.

These modifications in the field of exchange are just a few of the changes that occur in international business under the influence of international efforts to mitigate climate change. Emission trading has doubled the effect for legal entities. On one hand, companies work with care for the environment and comply with legal requirements; on the other hand, they have the opportunity to generate revenue from waste products of their activities, which would otherwise have created additional cost for them.

\begin{tabular}{|c|c|c|}
\hline & Emission trading exchange & Commodity exchange \\
\hline Subject of trade & Emission allowances & $\begin{array}{l}\text { Qualitatively similar and } \\
\text { exchangeable goods }\end{array}$ \\
\hline $\begin{array}{l}\text { Physical presence of the } \\
\text { goods }\end{array}$ & Only virtually & Not necessary \\
\hline Type of market & Primary and secondary & Only one market; \\
\hline Participants in the trade & $\begin{array}{l}\text { Owners of the credits (the } \\
\text { companies themselves) } \\
\text { Intermediaries (brokers and } \\
\text { dealers) }\end{array}$ & $\begin{array}{l}\text { Intermediaries (brokers and } \\
\text { dealers) }\end{array}$ \\
\hline Guarantees for quality & $\begin{array}{l}\text { Provided by the state 's } \\
\text { competent authorities after recite } \\
\text { of verification reports prepared } \\
\text { by independent consultants }\end{array}$ & Approved standards \\
\hline Legal state & $\begin{array}{l}\text { Public; } \\
\text { private }\end{array}$ & $\begin{array}{l}\text { Public; } \\
\text { private }\end{array}$ \\
\hline Clearing system & Yes & Yes \\
\hline Accounts & $\begin{array}{l}\text { Bank account; } \\
\text { "Goods" account }\end{array}$ & Bank account \\
\hline
\end{tabular}

\section{Conclusion}

Nowadays, the sustainable development issue is very popular and controversial. The idea of preserving the nature for the future generations, while still achieving economic growth and high lifestyle, is an idea that is present in every sector of the contemporary life and in the speech of all politicians, economists, and businessmen. Nowadays, everything is "green." In this context, the international business does not make any exception. As discussed in the previous sections, the sustainable development and the measures for environmental protection in particular result in different modifications in its forms. Due to the different activities on national and international level to preserve the environment, new "production resources" emerge such as waste and waste emissions. The waste as such is already seen as a business opportunity, as a raw material in a number of industries, or as just some useless production by-product. The same is also true for greenhouse emissions. They also have 
become tradable commodity and their trade has led to the emergence of a new type of exchange- - the emission trading exchanges.

Different mechanisms for reducing the amount of air emissions, for minimizing the waste, and for protecting the environment as a whole, provide companies with an opportunity to earn extra income, open new market niches, and lead to changes in the actual object of international transactions (environment pollutants as profitable "commodity"). Sustainable development, with an emphasis on environment protection, also results in numerous modifications in different aspects of business operations. Such modifications are in the supply chain, wherein a new chain called "waste chain" is created. There are certain changes in the import-export relationships and a new type of "contract" appears between these parties.

In the field of climate change mitigation, apart from the new type of exchange, there are a lot of modifications that are made in the classic commodity exchanges in order for this specific type of exchange to be able to function properly. At the same time, these measures achieve the main objective for which they were designed - to reduce the harmful effects of human activity on nature and to create opportunities for respective business entities to be able to operate sustainably.

\section{References}

Bartelmus, P. (1994). Environment, Growth, and Development: The Concepts and Strategies of Sustainability. Routledge. doi:10.4324/9780203419397

Boeva, B. (2004). Mezhdunaroden menidzhmŭnt [International management]. UI Stopanstvo

Davcheva-Ilcheva, N., \& Ilchev, L. (2005). Ekologiya. Ustoichivo razvitie. Okolna sreda [Ecology. Sustainable development. Environment]. Izdatelstvo Iztok-Zapad

Faße, A., Grote, U., \& Winter, E. (2009). Value Chain Analysis Methodologies in the Context of Environment and Trade Research. Discussion Paper No. 429, Gottfried Leibniz University of Hannover. Institute for Environmental Economics and World Trade.

Gechev, R. (2005). Sustainable Development: Economic Aspects. University of Indianapolis Press.

Heindl, P. (2012). Transaction Costs and Tradable Permits: Empirical Evidence from the EU Emissions Trading Scheme. Discussion paper, Center of European Economic Research

Karakasheva, L., Mencheva, L., Dinkov, D., \& Markova, B. (2005). Mezhdunaroden biznes [International Business]. Izdatelska kŭshta Prizma

Mahutga, M. (2011). When Do Value Chains Go Global? A Theory of the Spatialization of Global Value Chains. Blackwell Publishing Ltd. \& Global Networks Partnership.

Papadopoulos, P. (2011). Role and Function of Stock Markets: Using the Exemplar of London Stock Exchange and Frankfurt Stock Exchange. GRIN Verlag

Pearce, D. W., Barbier, E. B., \& Markandya, A. (1990). Sustainable Development: Economics and Environment in the Third World. Edward Elgar Publishing.

Pinkse, J., \& Kolk, A. (2007). Multinational Corporations and Emission Trading: Strategic Responses to New Institutional Constraints. European Management Journal, 25(6). doi:10.1016/j.emj.2007.07.003

Rakovska, M. (2007). Modelŭt na prilozhenie na upravlenieto na verigata na dostavkite v bŭlgarskata stopanska praktika [The model of application of the supply chain in the Bulgarian economic practice]. Ikonomicheski alternative, 5, 62-76

Report of the World Commission on Environment and Development. (1987). Our Common Future. Retrieved March 20, 2012 from http://www.un-documents.net/our-common-future.pdf

Stiglitz, J. (2006). Making Globalisation Work. Penguin Group

Wang, F., Huisman, J., Meskers, C. E., Schluep, M., Stevels, A., \& Hagelüken, C. (2012). The Best-of-2-Worlds Philosophy: Developing Local Dismantling and Global Infrastructure Network for Sustainable E-Waste Treatment in Emerging Economies. Waste Management, 32(11), 2134-46. doi:10.1016/j.wasman.2012.03.029 